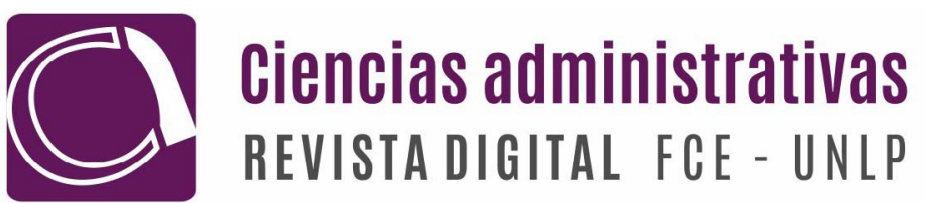

RESEÑA

\title{
LA FATIGA Y SUS PROYECCIONES SOCIALES. PALACIOS, ALFREDO L.'
}

A casi un siglo de la aparición de La Fatiga y sus proyecciones sociales de Alfredo L. Palacios (1a edición de mayo de 1922 publicada por la Facultad de Ciencias Económicas de la Universidad de Buenos Aires), esta obra merece ser recordada y analizada nuevamente.

Es un libro fundamental y excepcional. Fundamental porque consiguió incrementar el conocimiento en el área de lo que hoy se denomina "ciencias del trabajo"; básicamente trasladó el laboratorio a la realidad, la fábrica, y replicó los experimentos cruciales de la disciplina de su época confirmando los resultados sobre la fatiga fisiológica y psicológica en los obreros y utilizó los resultados empíricos para criticar algunos supuestos teóricos del taylorismo, además de las aplicaciones que realizó en diversos ámbitos como la enseñanza, en particular la del derecho, y en el fundamento de leyes laborales.

Excepcional porque obtuvo estos logros sin ser un especialista en algunas de las áreas básicas en las cuales trabajó. Porque su aguda capacidad y sus ideales de reformar la sociedad, especialmente en lo que toca al trabajo obrero, fueron los impulsores de su magnífica obra. Por el notable clima intelectual y organizacional de la Facultad de Ciencias Económicas que le permitió, en una universidad que todavía era criticada por su falta de investigación desinteresada y extremo profesionalismo, obtener los resultados de ciencia básica que hicieron progresar el campo de estudio y realizar experimentos en sentido estricto justamente en una facultad que de antemano no era la mejor situada para realizarlos.

El libro tiene nueve capítulos y los cinco primeros tratan de cuestiones que abarcan desde los fundamentos filosóficos hasta económicos, legales o políticos del trabajo; los cuatro restantes se centran en el análisis de la fatiga psicofisiológica del trabajo en la fábrica a través de estudios experimentales.

En el capítulo primero analiza la justificación de Aristóteles del trabajo esclavo. Si existieran artefactos capaces de ejecutar tareas por sí mismos, obedeciendo órdenes o anticipando las instrucciones, como el mito presenta los trípodes de Efesto, el esclavo no sería necesario. Las máquinas, en el capitalismo, reemplazaron la fuerza humana

1. Editorial Claridad, 1944 (4⿳ạ ed.) [322 páginas]. (Trabajo original publicado en 1922).

- EDUARDO RUBÉN SCARANO https://orcid.org/0000-0002-0978-8290 eduardo.scarano@gmail.com

Centro de Investigación en Epistemología de las Ciencias Económicas. Facultad de Ciencias Económicas. Universidad de Buenos Aires. Argentina. 
y potenciaron extraordinariamente la eficiencia productiva, sin embargo, no trajeron la liberación del trabajo que vislumbró Aristóteles, sino que crearon una masa, el proletariado, que se fatiga y se agota.

En el segundo capítulo examina la economía política del trabajo y desde un enfoque marxista concluye que el capitalista utiliza la técnica para alargar la jornada de trabajo y conseguir reducir por el progreso técnico el intervalo que necesita para pagar su fuerza de trabajo $y$, al extenderla, aumentar el valor de su capital. También reclama contra la enseñanza y la cultura jurídica, excesivamente formales y muy poco basadas en los resultados de las ciencias empíricas con los cuales fundar las normas.

El tercer capítulo está íntegramente dedicado a la crítica del taylorismo. No desestima el estudio de tiempos y movimientos, pero considera muy limitado el enfoque de Taylor al no considerar la fatiga. Discute otro postulado básico del taylorismo, la posibilidad de armonía entre capital y trabajo.

En el cuarto capítulo describe la polémica acerca de la carestía de alimentos en el seno de la Organización Internacional del Trabajo, que se había creado hacía poco, en 1919. Los empresarios proponían la extensión de la jornada laboral a lo que se oponían los obreros. Decidieron estudiar el problema en cada uno de los países; su presidente dirigió a Palacios una invitación para hacerlo en Argentina. Este lo canalizó por la Facultad de Ciencias Económicas que crea una comisión para su examen y Palacios elige el estudio de la fatiga.

En el quinto capítulo presenta un panorama general sobre la fatiga y describe el plan de investigación experimental, el laboratorio, el lugar seleccionado y los sujetos experimentales.

En los dos siguientes capítulos expone los diferentes experimentos y presenta los resultados; el sexto lo dedica a la atención, el séptimo a factores fisiológicos ligados a la fatiga. El octavo, a las jornadas de las ocho horas y detalla el estudio empírico del efecto de la fatiga en el rendimiento, en especial cuando se las excede. En el último capítulo examina las perturbaciones que origina la fatiga.

A continuación, señalamos muy sucintamente algunas perspectivas notables que se encuentran en el libro que aún hoy son motivo de discusión. La más general es la defensa del trabajo como un medio no como un fin. Palacios reconoce que el capitalismo reemplaza la fuerza humana por la máquina, pero el trabajo continúa siendo el instrumento de la realización del individuo. La opción no consiste en modificar las condiciones de trabajo cambiando las relaciones sociales, el sistema, y mediante el trabajo recuperar y construir su humanidad. La alternativa es cambiar la sociedad y usar la técnica para liberarlo de la carga del trabajo y conseguir la autorrealización, el disfrute de la libertad. De esta manera se cumplirá la profecía de Aristóteles.

Desde la década de 1890 los trabajos pioneros de Marey, Freemont, Mosso, lotenko y Amar produjeron una corriente que desarrolló el estudio del trabajo industrial, en particular de la fatiga. El estudio principalmente en el laboratorio de los trabajadores se lo realizaba desde el punto de vista exclusivamente fisiológico. Así fundaron la ciencia del trabajo europea, que Palacios conoció y practicó al igual que la principal corriente americana, la fundada por Taylor. Si bien se valió de la mayoría de los supuestos e instrumental de la corriente europea, introduce la dimensión económica y política, es decir, propone un enfoque multidimensional, si bien no es el eje de su trabajo. Adicionalmente, aunque no es el pionero de los estudios del trabajo en Argentina, los lleva a un nuevo nivel y difunde el campo a toda América Latina.

Palacios no rechaza el estudio de los tiempos y movimientos del trabajador, pueden incluso llevar al diseño de una máquina que lo reemplace más eficientemente, pero critica su enfoque extremadamente limitado. Aumentar la productividad a través de la organización de movimientos y tiempos es una perspectiva restringida. No incluye la fatiga, por lo tanto, los factores fisiológicos, psicológicos, la dinámica que cambia el rendimiento a "largo plazo", ni la multidimensionalidad de los factores que propone Palacios para la comprensión del trabajo. También resalta lo limitado de la metodología de Taylor frente a la de la corriente europea, el método gráfico que permite obtener ergogramas o prosexigramas con información menos subjetiva, más precisa y más completa. Un supuesto básico de Taylor era la armonía, en ciertas condiciones, entre capital y trabajo. Palacios la considera una ilusión en este sistema aunque deja lugar para un reformismo progresivo principalmente mediante la aplicación de la ciencia y la lucha parlamentaria.

Los laboratorios que aplicaban el método experimental existían en el país, de hecho Palacios se valió del que funcionaba en la Facultad de Filosofía y Letras, pero establecerlo en una 
Facultad de Ciencias Económicas y desde una cátedra de derecho es un precedente significativo, sin antecedentes en ese momento en América y tampoco en Europa. Mostró la posibilidad de la investigación empírica más sólida, desde el punto de vista metodológico, en el área de los fenómenos económicos. Una línea de investigación que recién reaparecerá a fines del siglo pasado.

Independientemente de las teorías desde las cuales se enfocaba el trabajo, desde la escuela europea, hasta Taylor o Palacios, los resultados eran herramientas para aplicarlas en la intersección de las acciones políticas, sociales, económicas con el fin de reformar la sociedad y encauzar los conflictos agudos entre capital y trabajo de ese entonces. Palacios, como legislador, militante de un partido político, catedrático y en su práctica como abogado, ejemplificó magníficamente el uso de la ciencia para mejorar la sociedad.

Palacios posteriormente creó otro laboratorio en la Facultad de Ciencias Jurídicas y Sociales en la Universidad Nacional de La Plata con el fin de apoyar la enseñanza (ya era Decano desde 1922 y fue presidente de esa Universidad en 1941). Sus notables aportes no lo trascendieron y esta línea de trabajo paulatinamente se diluyó. Muestra una limitación de nuestra universidad en esa época, esencialmente profesionalista, la inmadurez de las disciplinas en la que el proyecto se cobijó, y la carencia de una organización explícita de la investigación que excediera los esfuerzos y la vocación individual. 